“C 2017 IEEE. Personal use of this material is permitted. Permission from IEEE must be obtained for all other uses, in any current or future media, including reprinting/republishing this material for advertising or promotional purposes, creating new collective works, for resale or redistribution to servers or lists, or reuse of any copyrighted component of this work in other works." 


\section{Predictive Voltage Control of Direct Matrix Converter with Reduced Number of Sensors for the Renewable Energy and Microgrid Applications}

\author{
Jianwei Zhang, Li Li and Zahra Malekjamshidi \\ Faculty of Engineering and IT \\ University of Technology Sydney \\ Sydney, Australia \\ Jianwei.Zhang@uts.edu.au,Li.Li@uts.edu.au
}

\author{
David G. Dorrell \\ Howard College Campus \\ University of KwaZulu-Natal \\ Durban, South Africa \\ Dorrelld@ukzn.ac.za
}

\begin{abstract}
This work proposes and investigates a renewable energy distributed generation system involving a matrix converter with an output filter working as a stable voltage supply. This is especially relevant for the stand-alone operation of a renewable energy microgrid where a stable sinusoidal voltage with prescribed amplitude and frequency under various load conditions is the main control objective. A controllable input power factor is preferred. In this paper, the model predictive control is employed to regulate the matrix converter output voltages which in turn are the supply for systems of the following stage. To reduce the number of required measurements and sensors, the work designs observers and makes use of the switch matrix. In addition to the regulation of the sinusoidal output voltages and input power factor, the control scheme deals with the common-mode voltage. The switching frequency is also considered in the controller to reduce the switching losses and keep the average switching frequency constant. In addition, the voltage transfer ratio can be improved at the cost of input current distortion. Supplying DC loads is feasible with this proposed control method. The controller is tested under various conditions including non-linear loads, DC loads and unbalanced input conditions to show it is effective, simple and easy to implement. Simulation results corroborate the effectiveness of the proposed controller and applications.
\end{abstract}

Keywords-Matrix Converter; Predictive Control; Voltage Regulation; Observers; Microgrid

\section{INTRODUCTION}

In the modern power industry, an interconnected power system can contain both AC and DC grids with power electronic converters interfacing different systems. An example is shown in Fig. 2. Renewable energy based distributed generation (DG) systems and microgrids are modern components in the distribution side of the system. HVDC and VAr compensation via devices such as STATCOMs can exist in both transmission and distribution and these require power electronic conversion. Only the largest of wind farms may be connected into the transmission system.

From the perspectives of reliable operation and control, the increasing interest in integration of renewable energy systems into a grid network imposes some challenges on the microgrid control [1]. Microgrids can operate in the grid-connected mode where the main control objective is the current or power exchange with the utility grid. They can also operate in the islanded mode, while the main control objective is to maintain the stable voltages for loads [2]-[4]. These modes depend on system operating conditions, users demand, availability of energy and utility grid requirement, etc. No matter in which operation mode, the microgrids should be able to supply electricity in a reliable, secure and economical manner [5]-[7]. To this end, power electronic converters play a critical role [8]. Various power electronic converters including multilevel inverters [9], together with their corresponding control techniques, have been researched for controlling power flow, current and voltage for microgrid applications [10].

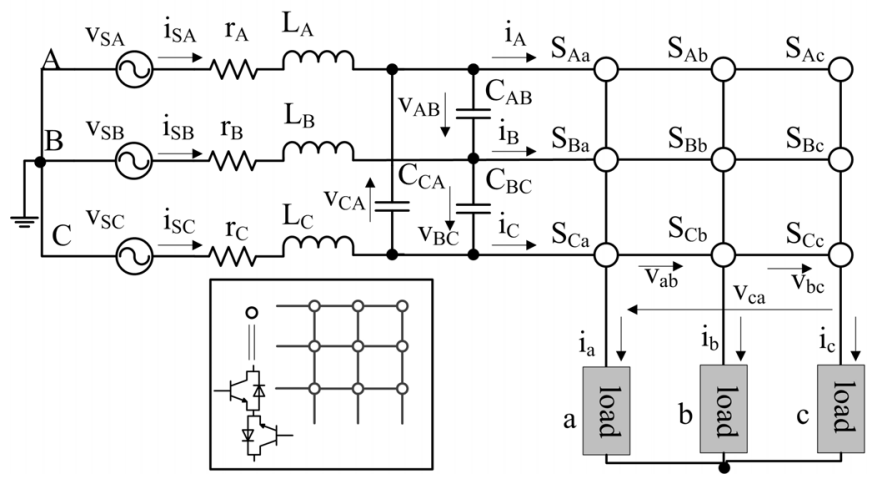

Fig. 1. A three-phase direct matrix converter system with input filters.

This work is mainly concerned with the islanded mode of a microgrid working as a stable voltage source to supply the various local loads, as depicted in Fig. 2. This AC microgrid may be connected to the grid network and other DGs via the point of common coupling (PCC). The DGs in a microgrid may include energy storage systems and renewable energy sources. Due to the intermittent nature of the renewable energy, the system input may suffer from disturbance and unbalance which should be considered in the control design to satisfactorily maintain the output voltage at a stable level. Currently a microgrid is an inverter-dominated system [3], [11]; on the other hand, it is difficult to maintain feed to the connected loads, particularly nonlinear loads, at anticipated voltage and frequency with an inverter [4]. In the literature, research projects on voltage source inverters (VSI) and neutral point clamped (NPC) inverters, with many control methods,

This work is supported in part by the China Scholarship Council (File No. 201406300161). 


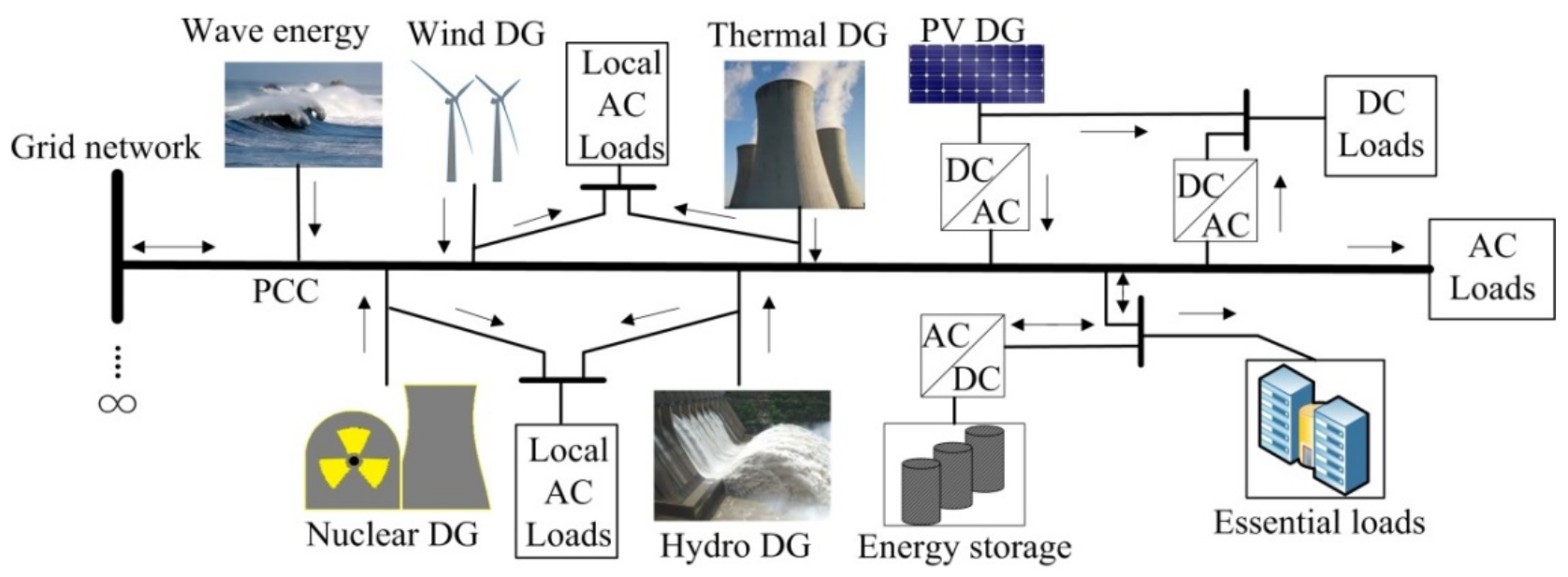

Fig. 2. Diagram of an interconnected power system example involving renewable DGs.

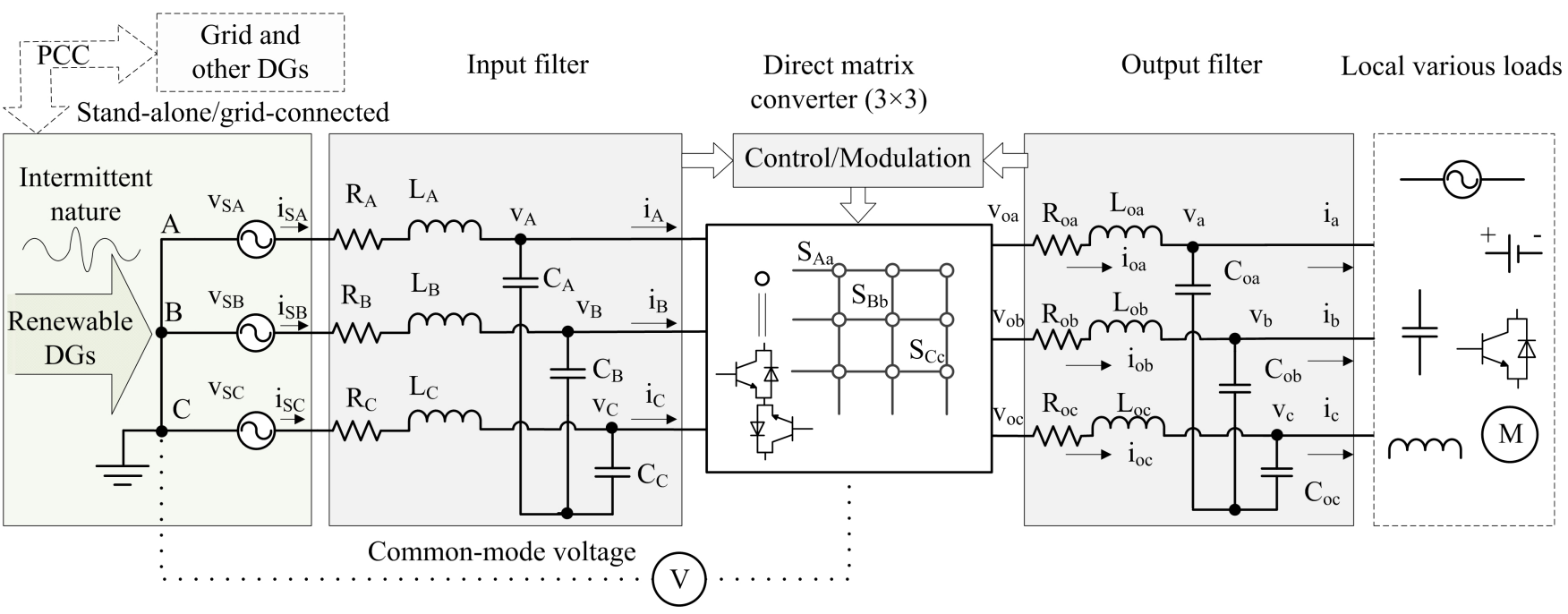

Fig. 3. AC microgrid with renewable distributed generators and matrix converter.

have been carried out on uninterrupted power systems (UPSs) based DGs in order to regulate the output voltage with LC filters [12], [13]. However, these are only suitable for a microgrid with DC DGs; otherwise, the rectifier stage and DC-link capacitor are required, which results in the necessity of the DC link voltage control. In addition, unidirectional power flow and the inability to control the input power factor are significant drawbacks of this structure.

In contrast, a direct matrix converter, shown in Figs. 1 and 2, features compact structure, bidirectional power flow, controllable input power factor being able to reach unity, regeneration capability and no energy-storage elements. A 3 by 3 matrix converter is quite flexible and can be used as a versatile converter to feed various loads such as inductive, capacitive, nonlinear, $\mathrm{AC}$ sources and even DC systems as shown in Fig. 2. It can be used for $\mathrm{AC} / \mathrm{AC}, \mathrm{AC} / \mathrm{DC}, \mathrm{DC} / \mathrm{AC}$ and even DC/DC conversion, although the number of switches for some specific applications (DC/DC converter) is too high compared with usual the converter used. However, it can always provide an interface between different systems with bidirectional power flow capability, which is not possible with many other converters. These matrix converter possibilities are hardly reported [14].
The matrix converter is a potential multi-function converter and has found several applications [15]. In terms of control of direct matrix converters, classic modulation methods including scalar modulation and pulse wave modulation (PWM) techniques usually are programmed offline; thus, these methods are vulnerable to the system and load variations causing steady-state errors [16]. The space vector modulation (SVM) has been widely researched and applied; however, the voltage transfer ratio limit is a drawback. Most of these methods do not provide sinusoidal output voltages, while the output current is the main control objective instead; neither can they handle the common-mode voltage which can be detrimental especially for the motor loads. This is diagnosed as one of the main reasons causing premature failures [17].

In this work, model predictive control (MPC) [18] is employed for the proposed application. This method does not require a modulation stage but can utilize all 27 available switch states in a matrix converter. MPC utilizes the system model to predict the system future behavior and select the optimum switch state by minimizing the predefined cost function. The design of the cost function in an MPC is flexible 
as it can contain many factors and constraints such as the variable errors depending on the specific applications [19].

The objectives and contributions of this paper are to develop a scheme for a matrix converter interfaced renewable energy DG system, and to propose a model predictive voltage control for a matrix converter in an AC microgrid, especially for the islanded mode supplying various loads. In the controller scheme, the common-mode voltage and averaging switching frequency are considered. The matrix converter is regulated to provide sinusoidal output voltages with an output filter. The number of required sensors is reduced by using observers. The unity input power factor can also be achieved under various conditions (loads and sources). The rest of the paper is organized as follows: Section II develops matrix converter and filters models; then observers are designed in Section III and the predictive voltage controller is designed in Section IV; Section V presents simulation results followed by conclusions in Section VI.

\section{System AND PREDICTION MODEL}

\section{A. Matrix Converter Model}

As shown in Fig. 1, a three-phase direct matrix converter consists of nine bidirectional semiconductor switches. The arrangement of these switches forms a $3 \times 3$ switch matrix as expressed

$$
\begin{aligned}
& {\left[\begin{array}{l}
v_{o a} \\
v_{o b} \\
v_{o c}
\end{array}\right]=} {\left[\begin{array}{lll}
S_{A a} & S_{B a} & S_{C a} \\
S_{A b} & S_{B b} & S_{C b} \\
S_{A c} & S_{B c} & S_{C c}
\end{array}\right]\left[\begin{array}{l}
v_{A} \\
v_{B} \\
v_{C}
\end{array}\right]=S\left[\begin{array}{l}
v_{A} \\
v_{B} \\
v_{C}
\end{array}\right] } \\
& {\left[\begin{array}{l}
i_{A} \\
i_{B} \\
i_{C}
\end{array}\right]=\left[\begin{array}{lll}
S_{A a} & S_{A b} & S_{A c} \\
S_{B a} & S_{B b} & S_{B c} \\
S_{C a} & S_{C b} & S_{C c}
\end{array}\right]\left[\begin{array}{l}
i_{o a} \\
i_{o b} \\
i_{o c}
\end{array}\right]=S^{T}\left[\begin{array}{l}
i_{o a} \\
i_{o b} \\
i_{o c}
\end{array}\right] } \\
& \sum_{X=A, B, C} S_{X x}=1,(x=a, b, c)
\end{aligned}
$$

where $S$ and its transpose $S^{T}$ are switch matrices by controlling which matrix converter output voltages and input currents can be regulated accordingly. The elements $S_{X x}$ in the switch matrix can be assigned a value of one for the on state and zero for the off state. Based on the measurements of $v_{A, B, C}$ and $i_{o a}$, ${ }_{o b}, o c, v_{o a, o b, o c}$ and $i_{A, B, C}$ can be calculated respectively, which will be used in the prediction models.

The conditions (3) are applied to exclude switch states that short-circuit the inputs (usually voltage sources) and that open-circuit the outputs (usually inductive loads). Otherwise, overcurrent and overvoltage will be generated which can damage devices. Therefore, there are 27 switch states allowable in the matrix which compose 27 control actions (finite control set) in MPC.

\section{B. Filters Models}

The MPC implementation is based on the system model. According to Fig. 3, the output filters of the matrix converter are modelled as

$$
\begin{aligned}
& \left\{\begin{array}{l}
v_{o a}-i_{o a} \cdot R_{o a}-L_{o a} \frac{d i_{o a}}{d t}=v_{a} \\
v_{o b}-i_{o b} \cdot R_{o b}-L_{o b} \frac{d i_{o b}}{d t}=v_{b} \\
v_{o c}-i_{o c} \cdot R_{o c}-L_{o c} \frac{d i_{o c}}{d t}=v_{c}
\end{array}\right. \\
& \left\{\begin{array}{l}
C_{o a} \frac{d v_{a}}{d t}=i_{o a}-i_{a} \\
C_{o b} \frac{d v_{b}}{d t}=i_{o b}-i_{b} \\
C_{o c} \frac{d v_{c}}{d t}=i_{o c}-i_{c}
\end{array}\right.
\end{aligned}
$$

The capacitors can be connected in either star or delta. The feature of the star connection is that the required capacitance is three times $\left(C_{A}=3 C_{A B}\right)$ while the voltage rating is $\sqrt{3}$ times $\left(V_{A B}=\sqrt{3} V_{A}\right)$ smaller of that in a delta connection (Fig. 1) for the equivalent ratings.

In order to simplify the modelling procedure, it is sufficient to consider a single-phase model due to the symmetry of the three-phase system. Hence (4) and (5) can be rewritten as the state space model:

$$
\begin{gathered}
{\left[\begin{array}{c}
\dot{i}_{o a} \\
\dot{v}_{a}
\end{array}\right]=F\left[\begin{array}{c}
i_{o a} \\
v_{a}
\end{array}\right]+G\left[\begin{array}{c}
v_{o a} \\
i_{a}
\end{array}\right],} \\
F=\left[\begin{array}{cc}
-R_{o a} / L_{o a} & -1 / L_{o a} \\
1 / C_{o a} & 0
\end{array}\right], G=\left[\begin{array}{cc}
1 / L_{o a} & 0 \\
0 & -1 / C_{o a}
\end{array}\right]
\end{gathered}
$$

where the voltages $\left(v_{o a}\right.$ and $\left.v_{a}\right)$, currents $\left(i_{o a}\right.$ and $\left.l_{a}\right)$, and filters $\left(L_{o a}, R_{o a}\right.$, and $\left.C_{o a}\right)$ are denoted in Fig. $3, F$ and $G$ are the state space matrices. Based on (6), the zero-order-hold based discretized model can be derived as follows.

$$
\begin{gathered}
{\left[\begin{array}{c}
i_{o a}[k+1] \\
v_{a}[k+1]
\end{array}\right]=A\left[\begin{array}{c}
i_{o a}[k] \\
v_{a}[k]
\end{array}\right]+B\left[\begin{array}{c}
v_{o a}[k] \\
i_{a}[k]
\end{array}\right],} \\
A=e^{F \cdot T_{s}}, \quad B=\int_{0}^{T_{s}} e^{F \cdot \tau} d \tau \cdot G
\end{gathered}
$$

where $T_{\mathrm{s}}$ is the sampling time and the matrices $A$ and $B$ can be obtained from

$$
\begin{gathered}
A=\left[\begin{array}{ll}
A_{11} & A_{12} \\
A_{21} & A_{22}
\end{array}\right] \\
A_{11}=\frac{a \cdot e^{a \cdot T_{s}}-b \cdot e^{b \cdot T_{s}}}{a-b}, \\
A_{12}=\frac{-\left(e^{a \cdot T_{s}}-e^{b \cdot T_{s}}\right)}{L_{o a}(a-b)}, \quad A_{21}=\frac{e^{a \cdot T_{s}}-e^{b \cdot T_{s}}}{C_{a b}(a-b)}, \\
A_{22}=\frac{a \cdot e^{a \cdot T_{s}}-b \cdot e^{b \cdot T_{s}}}{a-b}+\frac{R_{o a} \cdot\left(e^{a \cdot T_{s}}-e^{b \cdot T_{s}}\right)}{L_{o a}(a-b)}
\end{gathered}
$$




$$
\begin{gathered}
B=\left[\begin{array}{ll}
B_{11} & B_{12} \\
B_{21} & B_{22}
\end{array}\right], \quad B_{11}=\frac{e^{a \cdot T_{s}}-e^{b \cdot T_{s}}}{L_{o a}(a-b)}, \\
B_{12}=\frac{\left[a \cdot\left(e^{b \cdot T_{s}}-1\right)-b \cdot\left(e^{a \cdot T_{s}}-1\right)\right]}{\left(L_{o a} \cdot C_{o a} \cdot a \cdot b\right) \cdot(a-b)}, \\
B_{22}=\frac{-e^{a \cdot T_{s}}+e^{b \cdot T_{s}}+R_{o o} \cdot\left[a-b-a \cdot e^{b \cdot T_{s}}+b \cdot e^{a \cdot T_{s}}\right]}{\left(L_{o a} \cdot C_{o a} \cdot a \cdot b\right) \cdot(a-b)}
\end{gathered}
$$

with

$$
a, b=\frac{-R_{o a} / L_{o a} \pm \sqrt{\left(R_{o a} / L_{o a}\right)^{2}-4 / C_{o a} / L_{o a}}}{2} .
$$

Therefore, the future behavior of the output voltage $v_{a}$ can be predicted by

$$
\begin{aligned}
v_{a}[k+1] & =A_{21} \cdot i_{o a}[k]+A_{22} \cdot v_{a}[k] \\
& +B_{21} \cdot v_{o b}[k]+B_{22} \cdot i[k]
\end{aligned}
$$

which is derived from the discretized model (7). Similarly, the prediction model of the input current $i_{S A}$ using the input filter model can be obtained in (11) to predict the input current future behavior. Other matrices are derived in a similar manner where

$$
\begin{aligned}
i_{s A}[k+1] & =M_{11} \cdot i_{s A}[k]+M_{12} \cdot v_{A}[k] \\
& +N_{11} \cdot v_{s A}[k]+N_{12} \cdot i_{A}[k]
\end{aligned}
$$

The dimension of the models can be reduced from threephase model to $\alpha-\beta$ or $d-q$ model using frame transformations. Based on these predictions, MPC evaluates each switch state (27 in total as shown in Fig. 5) and selects the optimum one minimizing the cost functions to be applied at the next sampling instant. Variables can be obtained by measurements with sensors; if not, they can be estimated by using observers. It can be noticed that these prediction models require so many sensors. Fortunately, observers and switch matrix can be utilized in order to estimate some variables to reduce the number of sensors, thus cost.

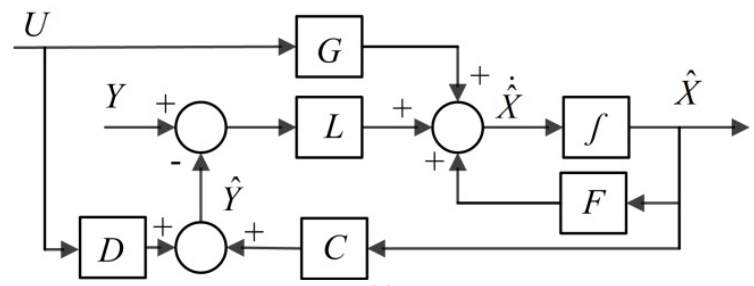

(a)

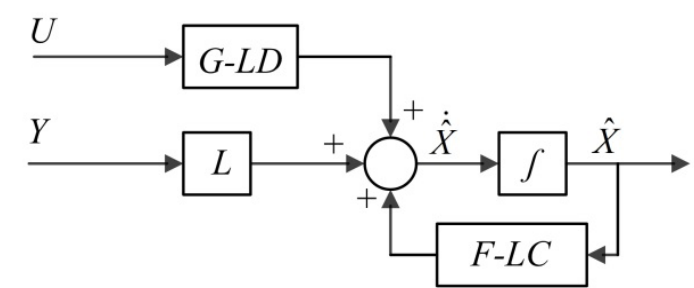

(b)

Fig. 4. Luenberger observer design (a) diagram and (b) simplified diagram.

\section{OBSERVERS DESIGN}

An observer is a dynamic system that can estimate the states of a system. For a system described in the state-space form

$$
\begin{aligned}
\dot{X} & =F X+G U \\
Y & =C X+D U
\end{aligned}
$$

the Luenberger state observer can be designed as illustrated in

$$
\begin{gathered}
\dot{\hat{X}}=F \hat{X}+G U+L(Y-\hat{Y}) \\
\hat{Y}=C \hat{X}+D U
\end{gathered}
$$

Substituting (15) into (14) results in

$$
\begin{aligned}
\dot{\hat{X}} & =F \hat{X}+G U+L(Y-\hat{Y}) \\
& =F \hat{X}+G U+L Y-L C \hat{X}-L D U \\
& =(F-L C) \hat{X}+(G-L D) U+L Y
\end{aligned}
$$

where $L$ is the observer gain matrix. According to (16), the observer diagram is shown in Fig. 4.

Depending on the specific observed state, the descriptions should be modified accordingly and some assumptions may be needed. In order to observe the load current $i_{a}$, for example, the assumption $\mathrm{d} i_{a} / \mathrm{d} t=0$ is made and added to the model (6) to make either a 2-D or 3-D observer. This assumption is based on the fact that the algorithm sampling time is sufficiently small, so the load current barely changes. The modified model based on this assumption is obtained as a 3-D observer model in

$$
\begin{gathered}
\dot{X}_{o}=\left[\begin{array}{l}
\dot{i}_{o a} \\
\dot{v}_{a} \\
\dot{i}_{a}
\end{array}\right]=F_{o}\left[\begin{array}{c}
i_{o a} \\
v_{a} \\
i_{a}
\end{array}\right]+G_{o} U_{o}, Y_{o}=C_{o}\left[\begin{array}{c}
i_{o a} \\
v_{a} \\
i_{a}
\end{array}\right]+D_{o} U_{o}, \\
F_{o}=\left[\begin{array}{ccc}
-R_{o a} / L_{o a} & -1 / L_{o a} & 0 \\
1 / C_{o a} & 0 & -1 / C_{o a} \\
0 & 0 & 0
\end{array}\right], \\
G_{o}=\left[\begin{array}{lll}
1 / L_{o a} & 0 & 0
\end{array}\right]^{T}, U_{o}=v_{a}
\end{gathered}
$$

A 2-D observer model can be derived similarly. Here, matrices $C_{o}$ and $D_{o}$ can be designed according to the desired outputs. The gain matrix $L$ in (16) should be designed properly so that eigenvalues of $F-L C$ are strictly on the left-hand side of the complex plane. Under this condition, the estimation error dynamics is asymptotically stable, which means the estimation error will decay to zero eventually. In this work, load currents $i_{a, b, c}$ and source voltages $v_{s A, s B, s C}$ are observed using the observers, and 2-D model based observers are adopted for simplicity.

\section{Predictive Voltage Controller Design}

In MPC a cost function is employed to optimize the selection of switch actions. The cost function design reflects the control objectives and priorities. In this work, the main control objectives are stable sinusoidal output voltages, in 


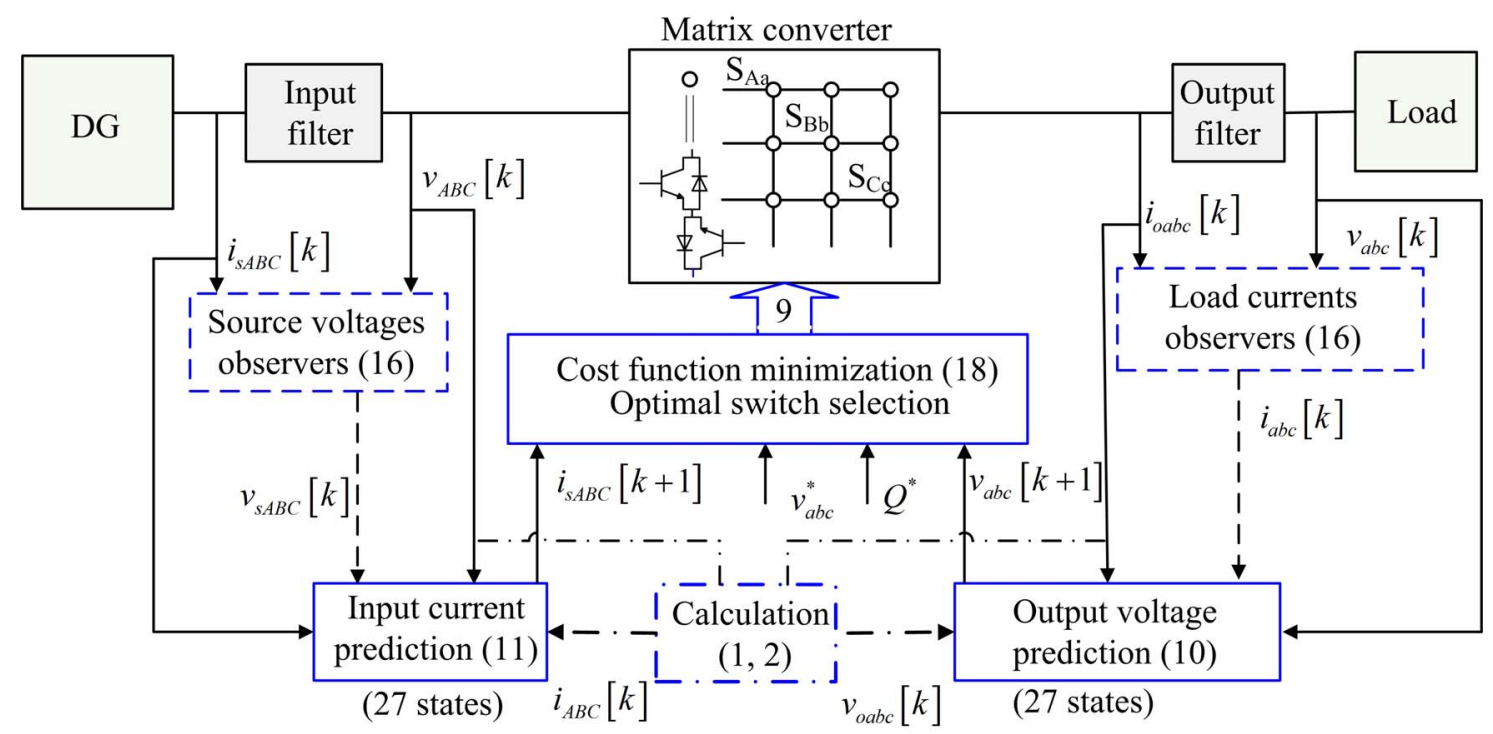

Fig. 5. The predictive voltage controller scheme for matrix converter in an islanded microgrid

TABLE I. SIMULATION SYSTEM AND CONTROLLER PARAMETERS

\begin{tabular}{rrrrrrrrrr}
\hline $\boldsymbol{v}_{\boldsymbol{s}}[\mathbf{V}]$ & $\boldsymbol{L}_{\boldsymbol{A}}[\mathrm{mH}]$ & $\boldsymbol{C}_{\boldsymbol{A B}}[\boldsymbol{\mu} \mathbf{F}]$ & $\boldsymbol{R}_{\boldsymbol{A}}[\boldsymbol{\Omega}]$ & $\boldsymbol{L}_{\boldsymbol{o} \boldsymbol{a}}[\mathbf{m H}]$ & $\boldsymbol{C}_{\boldsymbol{a b}}[\boldsymbol{\mu} \mathbf{F}]$ & $\boldsymbol{f}_{\boldsymbol{s}}[\mathrm{Hz}]$ & $\boldsymbol{f}_{\boldsymbol{o}}[\mathrm{Hz}]$ & $\boldsymbol{Q}^{*}[\mathbf{V A r}]$ & $\boldsymbol{T}_{\boldsymbol{s}}[\mathbf{s}]$ \\
\hline 380 & 3.2 & 2 & 0.5 & 4.8 & 10 & 50 & 60 & 0 & $1 \times 10^{-5}$ \\
\hline
\end{tabular}

addition to unity input power factor, elimination of the common-mode voltage, and low constant switching frequency. Different combinations can be considered for different applications. Therefore, the cost function for selecting the optimum switch state consists of four sub-functions and they are in the sequence described by

$$
\begin{aligned}
g & =\lambda_{1} \cdot\left\{\left|v_{a}^{*}-v_{a}^{p}\right|+\left|v_{b}^{*}-v_{b}^{p}\right|+\left|v_{c}^{*}-v_{c}^{p}\right|\right\} \\
& +\lambda_{2} \cdot\left|Q^{*}-Q^{p}\right|+\lambda_{3} \cdot\left|v_{N}^{*}-v_{N}\right|+\lambda_{4} \cdot \sum_{i=1}^{9}\left|S_{i}-S_{i}^{p}\right|
\end{aligned}
$$

where $v_{a, b, c}^{*}$, and $Q^{*}$ are references for the three-phase output voltages and input reactive power and their counterparts $v_{a, b, c}^{p}$ and $Q_{p}$ are the predicted values; $v_{\mathrm{N}}$ is the common-mode voltage shown in Fig. 3 and its reference is normally zero; $S_{i}$ is the current switch state and $S_{t}^{p}$ is the potential switch state to be applied; $\lambda_{1,2,3,4}$ are the weighting factors which determine priorities for each term. Terms with greater factors gain more regulation attention so performance tradeoff will take place among these terms. Designing these factors is usually empirical [20]. The cost function is not limited to this form; other terms such as integral, square and so on can be applied as well for specific applications.

According to the above analysis, the predictive voltage controller for the matrix converter in an islanded microgrid is illustrated in Fig. 5. Measured variable flows are denoted by the solid arrow lines while the dashed arrow lines represent the observed variable flows. Calculated variable flows are denoted in dot-dashed lines. Here a one-step prediction $[k+1]$ is demonstrated. It is worth noting that an algorithm sample delay should be compensated in the practical implementation [21].

\section{Simulation RESUlts}

Simulation results are presented in this section and various tests are implemented. The simulation parameters are tabulated in Table I. MPC controller parameters for each test are shown in the figure captions for clarity. Since this paper mainly concerns the islanded operation mode of the $\mathrm{AC}$ microgrid, stable voltages should be maintained under various load and input conditions.

The inductive load $\left(R_{l}=30 \Omega, L_{l}=10 \mathrm{mH}\right)$ was tested first. Fig. 6 shows the voltages response to a step command change from $200 \mathrm{~V}_{\mathrm{pk}}$ to $250 \mathrm{~V}_{\mathrm{pk}}$ at $0.05 \mathrm{~s}$. As seen from the figure, the dynamic response of output voltage is fast and it can track the prescribed reference effectively. The stable and sinusoidal voltages are obtained at load side. The input reactive power can be controlled to be zero, that is, a unity power factor is achieved as shown in Fig. 7. The distortion around $t=0.05 \mathrm{~s}$ is because of the command step change as appeared in Fig. 6 . The capacitive and resistive load tests demonstrate results that are quite similar to the inductive load. The observer results for $i_{a, b, c}$ are shown in Fig. 8 with good estimation performance.

The nonlinear load test is performed where an uncontrolled three-phase rectifier was used as a nonlinear load. In this case the rectifier input filters are required in a similar manner to normal rectifier applications. The steady-state voltage performance is shown in Fig. 9 where the supply voltages are regulated effectively for the nonlinear load. It is worth noting that DC loads can be supplied as well.

The disturbance caused by the renewable DG is considered in the following test. A disturbance signal of $50 \sin (50 \pi \mathrm{t}) \mathrm{V}$ is added into the three-phase source voltages to simulate the disturbance caused by the renewable sources. The unbalanced 
inputs can also be simulated. The load supplied is the same inductive load. The results are shown in Fig. 10. As seen, the stable voltages are still obtained at the load side.

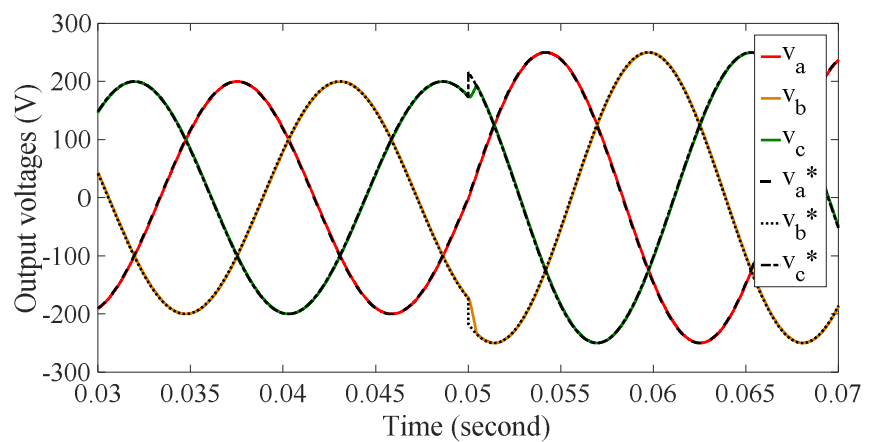

Fig. 6. Output supply voltage response with a step-change command at $t=0.05 \mathrm{~s} .\left(\lambda_{1}=1, \lambda_{2}=0.0067, \lambda_{3}=0, \lambda_{4}=0\right)$

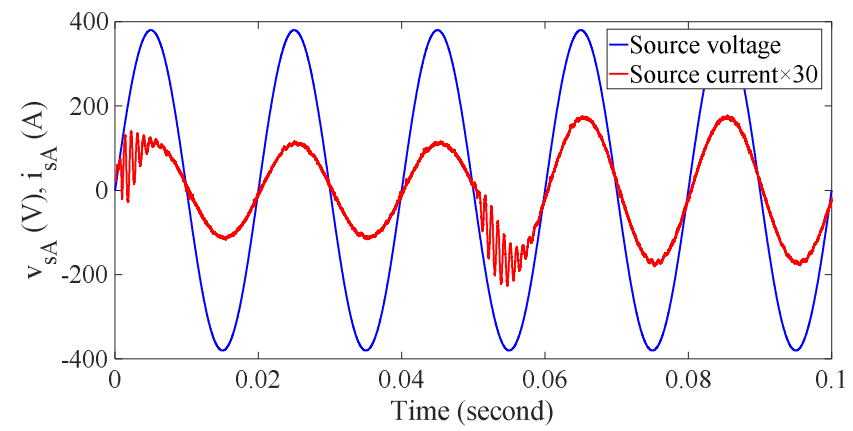

Fig. 7. DG source voltages and currents with a step-change voltage command at $t=0.05 \mathrm{~s} .\left(\lambda_{1}=1, \lambda_{2}=0.0067, \lambda_{3}=0, \lambda_{4}=0\right)$

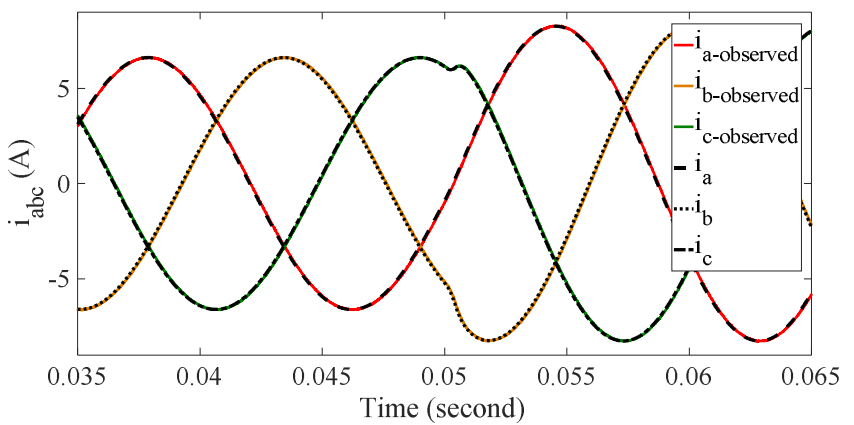

Fig. 8. Observers performance for output current $i_{a, b, c} .\left(\lambda_{1}=1, \lambda_{2}=0.0067\right.$, $\lambda_{3}=0, \lambda_{4}=0$ )

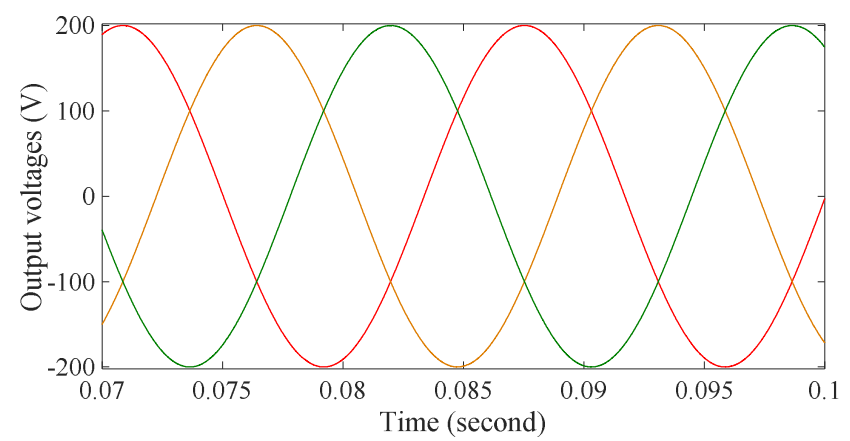

Fig. 9. Output voltages performance under a nonlinear load. $\left(\lambda_{1}=1\right.$, $\left.\lambda_{2}=0.0067, \lambda_{3}=0, \lambda_{4}=0\right)$
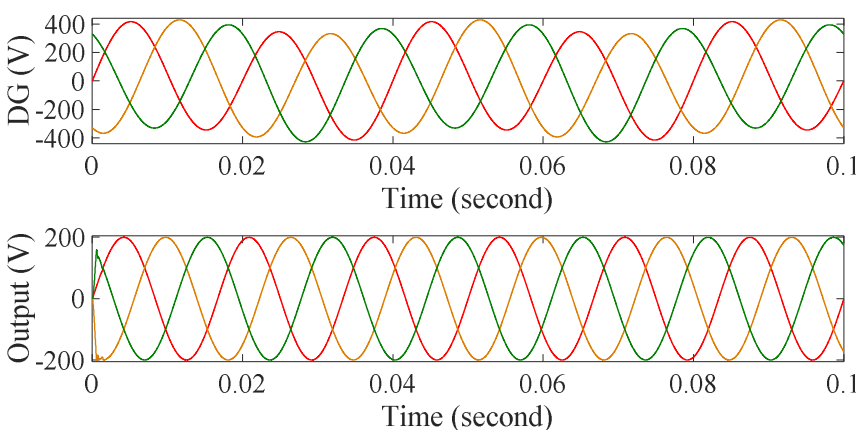

Fig. 10. Three-phase DG voltages with a a disturbance signal added, and regulated output voltages. $\left(\lambda_{1}=1, \lambda_{2}=0.0067, \lambda_{3}=0, \lambda_{4}=0\right)$
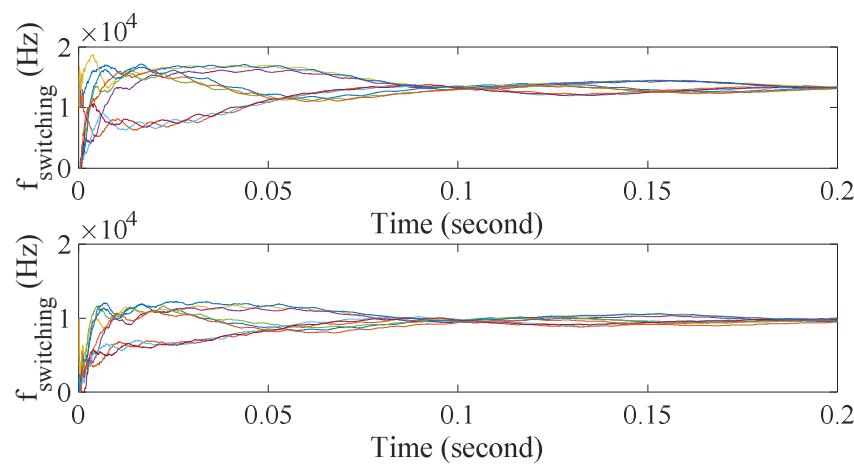

Fig. 11. Average switching frequency for 9 semiconductor switches with $\lambda_{4}=0$, and reduced frequencies with $\lambda_{4}=0.09$. $\left(\lambda_{1}=1, \lambda_{2}=0.0067, \lambda_{3}=0\right)$
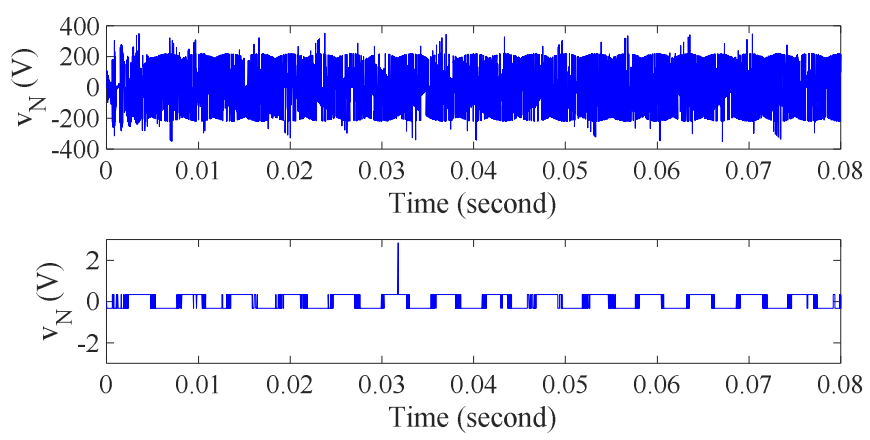

Fig. 12. Common-mode voltage with $\lambda_{3}=0$, and reduced common-mode voltage with $\lambda_{3}=2 . \quad\left(\lambda_{1}=1, \lambda_{2}=0.0067, \lambda_{4}=0\right)$

Comparative results for the averaging switching frequencies and common-mode voltage performance are shown in Figs. 11 and 12. The load is the same inductive load. The average switching frequency can be reduced efficiently and the common-mode voltage is nearly eliminated, as demonstrated in Figs. 11 and 12. The variable switching frequency of MPC is noticed. The reduced switching frequency will result in lower switching losses. The commonmode voltage reduction is beneficial to the motor loads. It is noted that the further improvement of these performances will sacrifice the performance of other objectives (trade-off among different control objectives). 


\section{CONCLUSIONS}

Matrix converter can be used as a versatile converter and multi-function interface with an appropriate control strategy. This work proposes a direct matrix converter based $\mathrm{AC}$ microgrid and its control especially for the islanded operation mode. The model predictive control is developed involving various control objectives including sinusoidal output voltages, unity input power factor, common-mode voltage and averaging switching frequency. The main control objective is to supply stable three-phase sinusoidal voltages to various loads including nonlinear loads. The disturbance at the inputs caused by the renewable DGs is also considered. Various tests validate the effectiveness of the matrix converter when applied in a microgrid. Moreover, the Luenberger observers are adopted in the work to reduce the required number of sensors and their effectiveness is illustrated when used in a predictive voltage controller. The proposed controller is tested under various load and input conditions. Simulation results corroborate the validity and effectiveness of the proposed scheme.

\section{REFERENCES}

[1] D. E. Olivares, A. Mehrizi-Sani, A. H. Etemadi, C. A. Canizares, R. Iravani, M. Kazerani, A. H. Hajimiragha et al., "Trends in microgrid control," IEEE Trans. smart grid, vol. 5, no. 4, pp. 1905-1919, 2014.

[2] X. Dou, K. Yang, X. Quan, Q. Hu, Z. Wu, B. Zhao, P. Li, S. Zhang and Y. Jiao. "An Optimal PR Control Strategy with Load Current Observer for a Three-Phase Voltage Source Inverter," Energies 8, no. 8, pp. 75427562, 2015.a

[3] J. Huang, C. Jiang and R. Xu, "A review on distributed energy resources and MicroGrid," Renewable and Sustainable Energy Reviews, vol. 12, no. 9 , pp. 2472-2483, 2008.

[4] A. Trivedi and M. Singh, "Repetitive Controller for VSIs in Droop Based AC-Microgrid," IEEE Trans. Power Electron., DOI 10.1109/TPEL.2016.2619367, 2016.

[5] N. Hatziargyriou, H. Asano, R. Iravani, and C. Marnay, "Microgrids," IEEE power and energy mag., vol. 5, no. 4, pp. 78-94, 2007.

[6] B. Kroposki, R. Lasseter, T. Ise, S. Morozumi, S. Papatlianassiou, and N. Hatziargyriou, "Making microgrids work," IEEE power and energy mag., vol. 6, no. 3, pp. 41-53, 2008.

[7] N. Merritt, C. Chakraborty, and P. Bajpai, "New Voltage Control Strategies for VSC based DG Units in an Unbalanced Microgrid," IEEE Trans. Sustainable Energy, vol. 8, no. 3, pp., 1762-1770, 2017.

[8] J. Justo, F. Mwasilu, J. Lee and J. Jung, "AC-microgrids versus DCmicrogrids with distributed energy resources: A review." Renewable and Sustainable Energy Reviews, vol. 24, pp.387-405, 2013.
[9] L. Wang, D. Zhang, Y. Wang, B. Wu, and H. S. Athab, "Power and voltage balance control of a novel three-phase solid-state transformer using multilevel cascaded H-Bridge inverters for microgrid applications," IEEE Trans. Power Electron., vol. 31, no. 4, pp. 32893301, 2016.

[10] F. Bosio, L. Ribeiro, F. Freijedo, M. Pastorelli and J. Guerrero, "Discrete-Time Domain Modelling of Voltage Source Inverters in Standalone Applications: Enhancement of Regulators Performance by Means of Smith Predictor," IEEE Trans. Power Electron., DOI 10.1109/TPEL.2016.2632527, 2016.

[11] I. J. Balaguer, Q. Lei, S. Yang, U. Supatti, and F. Z. Peng, "Control for grid-connected and intentional islanding operations of distributed power generation," IEEE Trans. Ind. Electron., vol. 58, no. 1, pp. 147-157, 2011 .

[12] P. Cortés, G. Ortiz, J. Yuz, J. Rodríguez, S. Vazquez and L. G. Franquelo, "Model predictive control of an inverter with output filter for UPS applications," IEEE Trans. on Ind. Electron., vol. 56, no. 6, pp. 1875-1883, 2009.

[13] A. Pirooz and R. Noroozian, "Predictive voltage control of three-phase voltage source inverters to supply nonlinear and unbalanced loads," 6 th Drives Systems \& Technologies Conf. (PEDSTC), pp. 389-394, 2015.

[14] J. Zhang, L. Li, and D. Dorrell, "Investigation of Direct Matrix Converter Working as a Versatile Converter (AC/AC, AC/DC, DC/AC, DC/DC Conversion) with Predictive Control," In 43rd Annual Conference Industrial Electronics Society, IECON 2017. Unpublished.

[15] J. Zhang, D. G. Dorrell and L. Li, "Applications of the Direct Space Vector Modulation Controlled Matrix Converter as the Unified Power Flow Controller," The 8th Int. Conf. on Power Electron., Machines \& Drives (PEMD 2016), Glasgow, pp. 6, 2016.

[16] M. Hamouda, F. Fnaiech, K. Al-Haddad and H. Y. Kanaan, "Matrix converter control: A sliding mode approach." 30th Ann. Conf. Ind. Electron. Society (IECON 2004), vol. 3, pp. 2295-2300, 2004.

[17] S. M. Ahmed, H. Abu-Rub and Z. Salam, "Common-Mode Voltage Elimination in a Three-to-Five-Phase Dual Matrix Converter Feeding a Five-Phase Open-End Drive Using Space-Vector Modulation Technique," IEEE Trans. Ind. Electron., vol. 62, no. 10 pp. 6051-6063, 2015.

[18] J. Rodriguez, M.P. Kazmierkowski, J. R. Espinoza, P.Zanchetta, H. AbuRub, H. A. Young and C. A. Rojas, "State of the art of finite control set model predictive control in power electronics," IEEE Trans. Ind. Informatics, vol. 9, no. 2 pp. 1003-1016, 2013.

[19] S. Kouro, P. Cortés, R. Vargas, U. Ammann and J. Rodríguez, "Model predictive control-A simple and powerful method to control power converters," IEEE Trans. Ind. Electron., Vol. 56, no. 6, pp. 1826-1838, 2009.

[20] P. Cortés, S. Kouro, B. L. Rocca, R. Vargas, J Rodríguez, J. I. León, S. Vazquez and L. G. Franquelo, "Guidelines for weighting factors design in model predictive control of power converters and drives," Int. Conf. Ind. Tech. (ICIT 2009), pp. 1-7, 2009.

[21] P. Cortes, J. Rodriguez, C. Silva and A. Flores, "Delay compensation in model predictive current control of a three-phase inverter," IEEE Trans. Ind. Electron., vol. 59, no. 2, pp. 1323-1325, 2012. 